\title{
The IMA Study on the Life Cycle Assessment (LCA) of Magnesium
}

\author{
Horst E. Friedrich, Simone Ehrenberger \\ Institute of Vehicle Concepts, German Aerospace Centre (DLR), Pfaffenwaldring 38-40, 70563 Stuttgart, Germany \\ horst.friedrich@dlr.de
}

Extended abstract:

\section{Goal and Scope}

Magnesium shows considerable potentials as lightweight material for weight sensitive applications. To assess the potential environmental benefits of magnesium in transport applications, the International Magnesium Association (IMA) initiated a study on the life cycle assessment (LCA) of magnesium.

The goal of this study was to assess the environmental potential of magnesium as lightweight material for the use in road vehicles and aircrafts. For magnesium production and processing, up-to-date technologies are evaluated. Two application examples represent the use of magnesium in transport: a steering wheel for road vehicles and magnesium parts for an aircraft door. The evaluation of the end-of-life of magnesium parts aims to assess a representative recycling path for magnesium.

The overall life cycle of both magnesium parts is compared to aluminium as an alternative material. We focus on the impact assessment results for greenhouse gas $(\mathrm{GHG})$ emissions $\left(\mathrm{CO}_{2 \mathrm{eq}}\right)$.

\section{Life Cycle Steps}

Primary magnesium can be produced via thermal reduction or electrolysis. This study assesses the state of the art Pidgeon process of the year 2011 in China. The weighted result for GHG of the Pidgeon process according to the production figures in 2011 is $25.8 \mathrm{~kg}$ $\mathrm{CO}_{2 \mathrm{eq}}$ per kg primary magnesium. The use of production wastes from fuel production can be credited to the primary magnesium production. When applying this approach, the weighted average GHG emissions of the Pidgeon process is $19.9 \mathrm{~kg} \mathrm{CO}_{2 \mathrm{eq}} / \mathrm{kg}$ $\mathrm{Mg}$.

Furthermore, we evaluated a representative, state-ofthe art electrolysis process. The GHG emissions amount to $17.8 \mathrm{~kg} \mathrm{CO}_{\text {2eq }}$ per $\mathrm{kg}$ primary magnesium. When crediting the by-products of the process, the net emissions of the electrolysis for primary magnesium amount to $14.0 \mathrm{CO}_{2 \mathrm{eq}}$.

The study focuses on two exemplary applications for magnesium which also represent two different production routes for components. The steering wheel for cars is manufactured by die-casting. The door parts for aircrafts are manufactured via sand casting for which a separate energy and material flow model has been developed. Magnesium needs less energy and material for manufacturing compared to aluminium in both processes. Thus, GHG are lower as well. Concerning the end-of-life of the products, we focus on the evaluation of road vehicles. The end-of-life scenario influences the overall balance for automotive applications, whereas in case of aircraft components the emissions during the use stage are too dominant. After the end-of-life treatment, magnesium usually ends up in the light metal fraction together with aluminium.

\section{Overall Life Cycle Balance for Magnesium Use in Transport}

A major goal of using lightweight materials in transport is to save weight and fuel. We calculated the overall fuel reduction over a life mileage of 200,000 $\mathrm{km}$. All magnesium scenarios have lower greenhouse gas emissions over the whole life cycle of the steering wheel. The $\mathrm{CO}_{2 \mathrm{eq}}$ emissions are calculated as net differences to the aluminium reference. Magnesium made by electrolysis has lower emissions already during its production stage due to the fact that less material has to be produced. The average Pidgeon process with credits for the use of waste gases shows a break-even point of about $46,000 \mathrm{~km}$. The average Pidgeon magnesium without credits shows an advantage in the overall balance when end-of-life is included.

For the application of magnesium in aircrafts, the use as door parts in a middle haul aircraft has been analyzed. The higher emissions from production of the door parts are amortized after less than ten flights for all Pidgeon process based magnesium scenarios. The high energy consumption of aircrafts justifies the use of magnesium as lightweight material after a short time of operation.

\section{Conclusions}

The assessment of the current primary magnesium production shows that the processes have been subject to considerable technological improvements during the past years. The results show the positive effects of lightweight design in transport applications and the potentials of magnesium for such applications. Nevertheless, further improvements in the efficiency of the production process and the effective recycling of magnesium post-consumer scrap are necessary to enhance the environmental performance of magnesium. Recent developments of the existing magnesium production routes and plans for new production sites point in the right direction. 